\title{
Sociología y rock. Experiencias dentro del campo (2016-2018)
}

Sociology and rock. Experiences within the field of study (2016-2018)

Valeria Lucía Saponara Spinetta noblecaballera_vale@hotmail.com

http://orcid.org/0000-0003-4484-1584

Facultad de Ciencias Sociales; Universidad de Buenos Aires/

Consejo Nacional de Investigaciones Científicas y Técnicas/

Universidad Nacional de Avellaneda (Argentina)

\section{Resumen}

El artículo intenta reflexionar sobre experiencias acontecidas en mi trabajo de campo con músicos independientes de rock miembros de la Unión de Músicos de Avellaneda (UMA), en la localidad homónima (zona sur del conurbano bonaerense, Argentina), entre abril de 2016 y abril de 2018.

El objetivo es describir mi llegada al campo y ahondar en las particularidades que tiene trabajar con músicos y a la vez ser música. Al mismo tiempo, se profundiza en el modo en que el campo nos transforma al igual que, como cientistas sociales, lo transformamos.

Se aborda el vínculo entre experiencia, investigación y construcción de conocimiento, haciendo hincapié en la conexión entre las relaciones que entablamos, como investigadores, con los sujetos de investigación (relaciones de distancia e involucramiento) y las actividades que realizamos en el campo (observación y/o participación). Se sugiere así que la reflexión sobre el 
trabajo y las experiencias dentro del campo, desde la experiencia musical en sí misma, puede ser un aporte interesante para el campo antropológico y multidisciplinario.

Palabras clave: Músicos; rock; Avellaneda; campo.

\section{Abstract}

This work attemps to think over experiences that happened while researching on the field, along with independent rock musicians who are members of the Musician Union of Avellaneda (UMA), in the self-entitled district known as "Municipio" (located in the southern area of the Buenos Aires' outskirts - Buenos Aires, Argentina), between April 2016 and April 2018.

The objective is to describe my arrival to the field of study, and to go deeper into the peculiarities of working with musicians. At the same time, the study focuses on the way the field of study makes an impact on us, as we do the same on it as social scientists.

Through this work, the relation among experience, invetigation, and construction of knowledge is shown. Focus is set upon relationship established with investigation subjects (by distance or direct involvement) and field activities (observation and/or participation). To reflect on the importance of the work itself, and experiences on the field is suggested, this work may be of significance from an antropological point of view.

Keywords: Musicians; rock; Avellaneda; field.

Según Guber (2001: 23), "La historia del trabajo de campo etnográfico se asocia, en antropología, al estudio de culturas exóticas, y en sociología, a segmentos marginales de la propia sociedad". Desde perspectivas muy diversas se ha hablado de la observación participante en tanto técnica para estudiar la alteridad. La posición clásica, representada por Malinowski (1995), propone adoptar la perspectiva de los nativos; en este sentido, privilegia la sumersión del investigador en la vida de la comunidad que estudia como fuente de conocimiento antropológico. Por otro lado, el enfoque interpretativista de Geertz (1994) se centra en interpretar significaciones a través de la "descripción densa". Desde un posicionamiento teórico diferente, en este caso el posmodernismo, Clifford (1995) propone a la reflexividad como instrumento de conocimiento: 
El llamado postmoderno a la reflexividad supuso que el etnógrafo debía someter a crítica su propia posición en el texto y en su relato (account, descripción) del pueblo en estudio, bajo el supuesto de que lo que estamos capacitados para ver en los demás depende en buena medida de lo que está en nosotros mismos (Guber, 2001: 124).

Como se ha demostrado ampliamente en la historia de la antropología, la cultura debe ser abordada desde la experiencia. Clifford propone que el conocimiento debe "plantearse 'dialógicamente', vale decir, en permanente negociación y pluralidad de voces" (Guber, 2001: 124); de este modo, el antropólogo es igualado al nativo y desde allí habla sobre las experiencias cotidianas que suceden en el campo. En este sentido, la posibilidad de interpretar a los actores surge de la coexistencia en un mundo compartido, un mundo experiencial y significativo, entonces, la cultura se aprende viviéndola, al experimentar los sentidos nativos. Para acceder a los significados que los sujetos negocian e intercambian es necesario convivir, transmitir las vivencias en el campo y comportarse según las pautas de los nativos.

Desde perspectivas teóricas diversas, se advierte que el trabajo de campo (focalizado en la propia experiencia, participación e inmersión) es central para producir conocimiento y para dotar de validez científica a una investigación de corte etnográfico. Para Guber (2001), la observación participante, consiste en observar sistemática y controladamente todo lo que acontece y en involucrarse en actividades de la población. Según demuestra Zenobi (2010), para recolectar datos adecuados y construir conocimiento (reconstruyendo teóricamente la perspectiva de los actores) es necesario entablar con los "nativos" lazos de simpatía y relaciones armoniosas duraderas basadas en la confianza y empatía. En palabras de Balbi (2012), la autoridad etnográfica se funda en la experiencia de campo; la misma implica una observación participante (fusión entre experiencia personal intensa y análisis científico). Por su parte, Rockwell (1987: 20) dice que "la progresiva asimilación de referencias y sentidos locales del lenguaje es parte de lo que marca el avance en el trabajo de campo; las situaciones en que participamos 'ponen a prueba' el conocimiento local".

En mi caso particular de estudio, el mundo de los músicos independientes de rock (1) me resulta familiar, cuestión que me permite comprender el significado de lo que dicen y hacen dichos sujetos (en tanto "nativa" de un mismo espacio socio-cultural, comprendo y utilizo las categorías de mis entrevistados, dada mi experiencia en el campo del rock). Aunque también, es verdad que los sentidos son heterogéneos, entonces la familiaridad puede dificultar pensar o entender otras acepciones. Sostengo que es necesario explicar mi propia trayectoria en el ámbito del rock a fin de señalar como se da mi inmersión corporal en dicho campo, en función 
de diferentes perspectivas que privilegian a la experiencia como fuente de conocimiento (Rockwel, 1987; Clifford, 1995; Guber, 2001; Zenobi, 2010; Balbi, 2012).

Mi formación académica en Sociología fue paralela a mi experiencia como público y música de rock, en ambos ámbitos encontré lenguajes diferentes con interpretaciones sociológicas de la realidad. Siempre viví en el partido de Avellaneda (zona sur del conurbano bonaerense, Argentina); sin embargo, me trasladaba hacia Capital Federal, dado que allí apreciaba una "movida rockera" que no podía ver en mi ciudad de origen. Cursando la Maestría en Comunicación y Cultura unifiqué mis dos pasiones: el rock y la sociología. Mi proyecto de tesis tenía que ver con la perdida de actitud contestataria en el rock nacional durante las gestiones kirchneristas (2). En esos años no existían investigaciones al respecto, parecía que Cromañón (3) acaparaba todo estudio académico sobre el rock nacional. Realicé un estudio de caso, donde tomé a los músicos de Los Caballeros de la Quema (banda representante del rock contestatario de los años noventa) para analizar sus reposicionamientos políticos entre 2003 y 2015. Estos músicos manifestaron una valoración positiva de la política durante el kirchnerismo.

Mi experiencia de campo me demostraba que a partir de 2003, gran cantidad de artistas de rock nacional paulatinamente dejaron de expresar la tradicional actitud contestataria contra los gobiernos nacionales de turno. Recordemos que, históricamente, el rock nacional se opuso a los poderes constituidos, tomó como enemigo al poder político, la iglesia y la policía (Garriga Zucal y Salerno, 2008). A nivel mundial, el rock surgió "como una forma musical exclusivamente orientada a la juventud" (Keightley, 2006: 171) y definida por su oposición a lo adulto; representante simbólico de la sociedad de masas.

De este modo, evidencié que muchas y muchos artistas del ámbito musical tendieron a expresar adhesión a las gestiones kirchneristas debido a sus políticas y medidas identificadas como de inclusión social, de derechos humanos y de promoción cultural. Pero también, pude ver que gran cantidad se manifiesta en contra del Gobierno de la Ciudad de Buenos Aires (4), por sus medidas concebidas como de exclusión, control y persecución (5), y por la clausura de locales de música en vivo que perjudica a la actividad musical en general, y sobre todo a la producida de forma independiente. En este contexto, me tocó experimentar el cierre de muchos de los bares a los que asistía en tanto música y púbico. 


\section{El desarrollo y la particularidad de mi trabajo de campo con músicos independientes de rock de Avellaneda}

El trabajo de campo en el que se basa este artículo tiene que ver con mi vinculación con los músicos de la Unión de Músicos de Avellaneda (UMA), que se originó cuando me inserté en un grupo de investigación de la Universidad Nacional de Avellaneda (UNDAV )-el mismo aborda la producción musical independiente en el partido de Avellaneda-. La UMA es un colectivo de músicos -conformado en 2012- que, a fin de fomentar la música en vivo, articula con el Municipio de Avellaneda -cuyo intendente responde al Frente para la Victoria-, organizando fechas en espacios públicos, clubes barriales y en el Teatro Municipal. Es importante destacar que muchos de sus miembros asumen una militancia política (6).

El objetivo de mi investigación doctoral es comprender el vínculo entre las gestiones kirchneristas -a nivel nacional y municipal- y las prácticas, manifestaciones e interpretaciones políticas de los músicos independientes de rock de Avellaneda, desde 2012 hasta la actualidad. Centrándome en un enfoque etnográfico interpretativista (Geertz, 1994), busco interpretar las percepciones subjetivas, las prácticas y manifestaciones políticas de estos músicos. Recurro a datos insertos en entrevistas y percibidos en mi observación participante, ya que como refiere Sarrabayrouse Oliveira (2011), el antropólogo debe articular las explicaciones que los actores dan sobre lo que hacen con la observación de lo que hacen.

Las actividades de observación, participación e interpretación atraviesan mi investigación etnográfica; en ella intento describir y comprender los fenómenos sociales "desde el punto de vista del actor", para de esa manera construir analíticamente la perspectiva nativa, articulando mis concepciones teóricas con las perspectivas de los actores (Balbi, 2012). De este modo, la observación participante y la entrevista en profundidad son las técnicas de obtención de información mediante las que trato acceder a los sentidos que los músicos le asignan a sus prácticas. Siguiendo los lineamientos antes expuestos, en mi trabajo de campo, priorizo mi experiencia, mi presencia e involucramiento en la población, lo cual me brinda conocimiento de primera mano y me posiciona como participante, además, garantiza la confiabilidad de los datos recogidos.

Considero que el trabajo de campo es una relación social que se construye en la interacción, es un proceso de socialización, en tal sentido, mi desempeño como música me permite interactuar y construir relaciones sociales particulares con los sujetos que estudio, a su vez, facilita mi presencia en el campo y el desarrollo de charlas ocasionales que me permiten 
acceder a las interpretaciones políticas de los músicos y los significados que les otorgan a sus vínculos con el Estado. Tal como refiere Sarrabayrouse Oliveira (2011), ante mí, el "campo" apareció como una red de relaciones sociales, como un espacio practicado, un "lugar".

La particularidad de mi trabajo de campo es que además de observar la cotidianeidad de los músicos, participo de esa realidad desde mi rol como música; de este modo, converso y entablo relaciones con esos sujetos, pero también frecuento sus espacios de sociabilidad (comparto actividades, salidas, recitales), lo cual posibilidad la empatía, central para recolectar datos y construir conocimiento (Zenobi, 2010). Al ser música accedo a las situaciones que quizás los sujetos que estudio le ocultarían a un investigador ajeno a la actividad musical, en este sentido Rockwell (1987: 8) plantea que la confianza "va permitiendo presenciar situaciones en que se manifiestan procesos y conflictos normalmente ocultados frente al extraño". Pero también, es cierto que, al ser parte del campo y conocer mis posicionamientos, puede ocurrir que los músicos me oculten ciertas cosas.

Mi acceso al campo se dio en dos momentos con consecuencias diferentes. En 2016 realicé por primera vez trabajo de campo en mi ciudad, entrevisté a músicos y realicé observación participante durante reuniones de la UMA. Sin embargo, pese a mi incumbencia académica, estaba fuera de ese mundo de rock local, dado que no experimentaba la "movida rockera" desde dentro (no conocía a los músicos, salas de ensayo y salas de concierto).En cambio, en 2017comencé a tocar en una banda local, cuestión que me brindó contactos e información y, a la vez, me abrió las puertas al campo, dado que desde entonces, pasé a conocer y pertenecer a ese universo de rock local (pudiendo visualizar sus luchas internas). Pasé a ser reconocida y aceptada como alguien que además de realizar una investigación, toca un instrumento musical, entonces mi relación con los músicos cambió y pase a ser una colega. La entrada al campo me influyó tanto que hasta transformó mi práctica personal, y en este proceso yo también modifiqué al campo dado que pasé a participar en él. Actualmente mi campo está en Avellaneda al igual que mi actividad musical.

\section{Dos momentos en la presentación y presencia en el campo. De la simple observación al compromiso con la organización}

Tal como expliqué, inicialmente me sentía extraña haciendo trabajo de campo en Avellaneda, sentimiento que fue mutando a medida que, en tanto música, transité y redefiní situaciones. 
Según Rockwell (1987: 6), "la definición de las situaciones en el campo depende de la capacidad para explicitar ante los habitantes de la localidad quién es uno y qué sentido tiene el trabajo que se emprende". Ante los músicos, con el paso del tiempo, me pude presentar como quien estudia sus prácticas pero también como alguien que comparte la actividad musical.

Rockwell (1987: 7) afirma que la entrada al campo marca la experiencia de campo, "contribuye a la definición de esa experiencia y de la información que se consigue". En este sentido, mi entrada inicial en tanto investigadora fue redefinida a medida que los músicos me vieron tocar en vivo. Al inicio de mi trabajo de campo, la observación era mi principal actividad, ya que desconocía la escena, cuestión que se revirtió con mi actuación en tanto música; fue entonces cuando cobró centralidad mi participación en el campo.

En las primeras reuniones de la UMA a la que asistí, me presenté como "una investigadora que estudia el vínculo entre el rock y la política". Mi actitud se limitaba a observar (debido a la distancia que mantenía con los músicos y que ellos me demostraban). Registraba lo que veía y escuchaba, pero no expresaba opiniones. Durante el segundo año en el campo, los miembros de UMA me reconocieron progresivamente como un par, dado que me desempeñaba como música. Me invitaban a actividades, a tocar en vivo y compartía con ellos charlas informales.

En tanto mi faceta artística estaba adentro de la sociedad estudiada; sin embargo, aunque creía estar sumergida en este mundo, esa inmersión era parcial, ese campo subcultural me antecedía y así me lo demostraba. Tal como la experiencia que relata Zenobi (2010), en mi pretensión de estudiar a los músicos, entré a un campo de relaciones sociales previas a mi incursión y mi persona estaba siendo evaluada.

Durante mi segundo año en el campo, un integrante del Consejo Directivo de la UMA me comentó sobre su participación en la primera reunión de la Mesa de Gestión y Coordinación de Músicos de Avellaneda (7). Fue entonces cuando le solicité que me facilite participar en ese espacio, dada la importancia que tendría para mi investigación. Aproveché para solicitar acceso a registros internos sobre las actividades que realiza la UMA (a fin de reforzar lo dicho por los músicos en las entrevistas). En ese momento, el músico me manifestó inquietudes sobre mis intenciones y sentí que se me demandaba un compromiso con la organización, que en tanto investigadora no asumía.

La cooperación y el compromiso son categorías nativas centrales que para los miembros de la UMA deben asumir los músicos; en cambio, el no comprometerse es un atributo negativo que les asignan a los músicos ajenos a la organización y desligados de la participación política. Esas categorías recayeron sobre mi persona y se me demandó "cooperar" con la organización. 
Según Perelman (2013: 181), "los modos y sistemas clasificatorios dan sentido a la vida de las personas, organizan el universo simbólico y de acción, incluyen y excluyen". En tal sentido, mis vínculos con la UMA deben ser entendidos bajo esas tensiones internas que son previas a mi llegada al campo. Es en función de estos términos nativos que cambiaron mi involucramiento y la percepción que los músicos tenían de mi persona. Estas categorías locales fueron centrales en mi trabajo de campo, porque insistentemente emergían en las reuniones y charlas con los músicos de la UMA -quienes le atribuyen significaciones importantes-, y porque me obligaron a cambiar mi posición con respecto a la organización de músicos; y esto fue lo que me permitió registrar la centralidad de estas nociones.

Tal como expliqué, el vínculo que me ligaba con la UMA se fue transformando. En mi primera presentación, los músicos no me conocían ni sabían sobre mi trabajo. En cambio, durante el segundo año los músicos sabían sobre mi profesión académica y musical, me habían visto y habíamos compartido charlas y escenarios. Pasé de ser observador participante a participante observador. Según Guber (2001: 57): "La diferencia entre observar y participar radica en el tipo de relación cognitiva que el investigador entabla con los sujetos/informante y el nivel de involucramiento que resulta de dicha relación". La experiencia de tocar en Avellaneda se transformó en el punto de inflexión en mi relación con los informantes. Mi participación en tanto música creó un vínculo de familiaridad que me permitió ingresar e integrarme a la lógica nativa, pero ese vínculo debía ser retribuido de algún modo.

Los músicos sabían que mi participación en las reuniones tenía por objeto producir conocimiento sobre la actividad musical local, y que por ello establecía relaciones y lazos sociales con ellos. Del mismo modo que para los miembros de la UMA entablar relaciones de cooperación e involucramiento con otros músicos es importante para desarrollar la actividad musical local, en esta etapa de mi trabajo de campo, para mí y para ellos era importante que estableciéramos vínculos cooperativos. Así, involucramiento e investigación fueron partes de un mismo proceso de conocimiento social.

Los miembros de la UMA me involucraron con el colectivo, terminé asumiendo tareas que ensancharon mi rol como investigadora. Me convocaron reiteradas veces a exponer mis reflexiones teóricas en el programa radial de la organización. Así, deje de ser simple observador pasivo y di a conocer mi voz, que era valorada por los miembros de la UMA en tanto responde a un saber académico. El vínculo que establecí con la UMA tomó la forma de un intercambio recíproco y colaborativo; yo era presentada como integrante de la UMA y 
participaba en tanto vocera de las acciones del colectivo, y ellos habilitaban mi participación en otros espacios como la Mesa de Gestión.

En este sentido, el campo dejó de ser sólo un ámbito de recolección y construcción de datos y pasó a ser un espacio de trabajo colaborativo conjunto. Lo dicho se consolidó cuando en mi tercer año de trabajo de campo en Avellaneda, durante una reunión extraordinaria, la UMA conformó la nueva comisión directiva, y en ese momento se me asignó un rol dentro de la misma.

Lo dicho hasta aquí me permite advertir que la inmersión en este campo tomó características provistas por los conceptos locales (de colaboración y compromiso) y, al mismo tiempo, el ser nativa además de investigadora, me posibilitó experimentar de formas específicas esos conceptos. En este sentido, el vínculo entre experiencias y conceptos es de vital importancia, así como también lo es el pendular dinámico entre involucramiento y distancia.

\section{Exotizar el rock: tensión distancia-involucramiento}

El trabajo de campo aquí presentado está marcado por la tensión distancia-involucramiento, dado que por mi práctica musical y rutinaria, me acerco a las formas de vida de la población a la que estudio. Es menester destacar también, la tensión que habría por el involucramiento y el compromiso que asumí con la UMA, ya que es posible que mi vínculo con los músicos no alineados a la actividad política de la organización se vean obstaculizados, dado que pueden identificarme como un integrante de la Comisión Directiva de la UMA y no como una investigadora que realiza trabajo de campo en Avellaneda.

A su vez, este posicionamiento, que me permite entender ciertos conceptos locales, también dificulta desnaturalizar otros. Según Guber (2014: 25), "investigar es estar dispuestos a descubrir y a revelar cómo nuestras reflexividades inciden en nuestro conocimiento de los demás". Reflexividad designa:

la capacidad de "reflexionar", "objetivar" o "concebir" el propio lugar en el campo y la incidencia de las condiciones socioculturales del/a investigador/a en el texto final, dando cuenta [...] de un proceso de conocimiento que se redefinía como intersubjetivo entre investigador/a y sujetos de estudio (Guber, 2014:16). 
El ámbito del rock es para mí un espacio conocido, por eso debo "descotidianizar" (desnaturalizar) las categorías nativas para revelar los elementos constitutivos de la realidad social de los músicos. Tal como refiere Lins Ribeiro (1989: 195), el antropólogo, al estudiar "su" propia sociedad busca "convertir lo familiar en exótico, usando -por principio y por racionalización metodológica- una posición de extrañamiento". En un primer momento desconocía la "movida rockera" local, pero cuando participé del campo y me inserté como una más, mi mirada cambió radicalmente, y esto tiene que ver también con deconstruir el propio sentido común.

No es sencillo lograr que el sentido naturalizado por el investigador no interfiera en la producción de los datos y en la construcción del conocimiento. Pondré un ejemplo; en una ocasión, un investigador se sorprendió con el hecho de que los músicos independientes entrevistados manifestaran tocar en público una vez por mes, dado que no podía comprender cómo hacían para organizar y preparar tantas fechas. Según Fonseca (2005), interpretar el mundo está permeado por nuestras trayectorias de vida, por nuestros preconceptos. En este sentido, a mí no me pareció inusual ya que comparto esa experiencia, y en tanto música participo de esa conciencia práctica (Lins Ribeiro, 1989). Por ende, mi acercamiento experiencial me dificulta problematizar esta práctica; mi involucramiento, desde lo musical y local, actúa facilitando pero también dificultando mi conocimiento.

Al ser parte del campo se me dificulta cuestionar otros imaginarios del sentido común, directamente relacionados con mi investigación, en este sentido, tiendo a naturalizar el hecho de que los músicos independientes de rock expresen identificarse con la gestión municipal, ya que coincido con su apreciación de que la misma se caracteriza por una activa política cultural. El tema, entonces, es reconocer los propios posicionamientos y poder problematizarlos.

Mi involucramiento en el campo suele ser un insumo peligroso aunque también de utilidad. En una ocasión, me tocó acompañar a un investigador a un ensayo; él había acordado realizar allí una entrevista. Yo sabía que esas condiciones no iban a ser favorables para el desarrollo del diálogo, dado que los músicos mientras ensayan se enfocan en tocar y no suelen estar atentos a conversaciones, a ello se le sumó el molesto ruido que quedó plasmado en la grabación. En el trabajo de campo la entrevista etnográfica suele hacerse en ámbitos familiares a los informantes, pero si el investigador no conoce cuál es el contexto adecuado, dejar que el entrevistado decida el lugar del encuentro puede ser peligroso. Es por ello que conocer el campo es un insumo que uso a la hora de considerar las posibles situaciones en que se da la conversación, me permite inferir qué momentos son los óptimos para entrevistar a los músicos. 
Es de destacar que no soy participante pleno, la implicación que asumo no me convierte en nativo (músico independiente de la UMA), porque no oculto mi rol de investigadora (comprometida con producir conocimiento académico valido a diferencia de los nativos). En cada situación intento ser reconocida como investigadora y marcar una distancia; así, trato de mostrarle al músico que está siendo investigado. En varias ocasiones, intentaron hacerme socia del colectivo, pese a que manifesté que no sería apropiado participar formalmente de la organización que estudio, terminaron asociándome, incluso me designaron un rol dentro de la comisión directiva. Lo dicho evidencia que, aunque saben mis intenciones académicas, me asumen como una más a causa de mi presencia y participación como música y también debido a la colaboración que esperan de mi parte. Estos conceptos nativos aplicados sobre mi persona, advierten cómo los informantes ejercen poder sobre la participación y el lugar de los etnógrafos. Según Clifford (1995), la autoridad etnográfica es caracterizada por este compromiso intersubjetivo y dialógico con los sujetos que estudio.

En tanto agente productor del campo que estudio, muchas veces intenté trazar una línea entre colega música y etnógrafa. Pude advertir que la mejor estrategia pasa por tratar de reconciliar mi rol de artista con el de cientista social, dado que soy música e investigadora al mismo tiempo. En este sentido, lo central de mi trabajo es que, el "estar alli" me permite construir conocimiento todo el tiempo, las diferentes situaciones de las que participo y que son parte del campo, hacen que tanto el diálogo casual como las entrevistas más formales que mantenga con los músicos sean un insumo central para mi investigación.

\section{Palabras finales}

En este artículo he intentado mostrar cómo la experiencia y participación de un investigador (en este caso, en el campo del rock) puede influir en la construcción de su proyecto de investigación. En el caso aquí relatado, primero incursioné en el ámbito del rock y luego me propuse realizar un trabajo sociológico sobre él. A través de mi experiencia musical pude observar y vivenciar un quiebre en la actitud contestataria de los y las artistas, que tenía que ver con la adhesión que muchos y muchas expresan hacia las gestiones kirchneristas. A través de mi observación participante fui definiendo eso que quería estudiar científicamente.

A lo largo de este artículo intenté describir mi llegada al campo, para tal fin narré mi trayectoria académica y musical. Tal como mencioné, mi incursión en el rock fue anterior a mi trabajo de 
investigación, sin embargo, cuando me centré en estudiar un colectivo de músicos las cosas cambiaron. Allí había relaciones y significados que yo desconocía y me atravesaban. Es relevante destacar que por más que comparto el mundo significativo del rock, en mi investigación local me vi obligada a resocializarme dado que el lugar geográfico (Ciudad Autónoma de Buenos Aires y conurbano bonaerense) marca significativas diferencias entre los músicos y las músicas de rock. A su vez, es de destacar que pasé a investigar a un colectivo de músicos que asume un compromiso político, entonces ese campo de relaciones era nuevo para mí y sus lógicas internas me atravesaban. Lo dicho demuestra que cada grupo social tiene particularidades y que el contexto influye en ellas, es así que cada campo es heterogéneo y homogéneo según sobre qué aspectos se haga foco.

Debí entonces entablar relaciones con esos sujetos, hacer que me reconozcan no sólo como alguien que los estudia sino también como un par. Ser música y que los sujetos de mi investigación me reconozcan como tal es lo que me abrió las puertas al campo y me permitió ser incluida como una más en el mundo que los músicos construyen en Avellaneda. Este trabajo demuestra la vinculación directa entre las relaciones que entablamos con los sujetos (de distancia e involucramiento) y las actividades que realizamos en el campo (observación y/o participación), a su vez, enfatiza el ejercicio de reflexividad que ello implica.

Me fue necesario reflexionar sobre mi presencia en el campo, como cambió en relación a los vínculos que fui estableciendo con los sujetos de mi investigación, como pasé de "estar fuera" a encontrarme "adentro", ser una más, y cómo ello me permitió producir distintos tipos de conocimiento, a la vez que me demandó desnaturalizar mis saberes y prácticas en ese ámbito (como por ejemplo, la frecuencia con la que los músicos independientes de rock realizan recitales). En este sentido, interpretar lo que me sucedió en el campo en tanto investigadora y lo que le sucedió a los sujetos de mi investigación, es decir lo que nos hizo la investigación, dado que el campo nos transforma y nosotras/os transformamos el campo, permite conocer más sobre ese mundo que intento interpretar.

Lo interesante es que a través de la escritura de este artículo pude visualizar cómo mi vida cotidiana era un obstáculo que no me permitía observar y acercarme a las dinámicas propias del mundo del rock en Avellaneda. Es decir, antes de realizar trabajo de campo en Avellaneda, yo enmarcaba mi experiencia personal, musical y profesional en Capital Federal, razón por la cual no podía conocer lo que pasaba en Avellaneda y por este motivo creía que no existía allí una "movida rockera". Pero una vez que mi participación en una banda de rock local me exigió participar, involucrarme y experimentar el rock en mi ciudad, en tanto música e investigadora a 
la vez, se modificó mi posición en el campo y mi mirada acerca del mismo -que me permite registrar ciertas cuestiones aunque me dificulta otras-, tal como intenté explicar en este artículo.

\section{Notas}

(1) En lo que sigue, me voy a referir a los músicos en masculino ya que los músicos independientes de rock miembros de la UMA entrevistados hasta el momento son varones y se autoperciben como tales. Es menester destacar que los músicos afiliados que participan activamente del colectivo son varones, a su vez, no se observan identidades disidentes ni femeninas.

(2) Refiere a las tres gestiones de gobierno de Néstor Kirchner (2003-2007) y de Cristina Fernández de Kirchner (20072011; 2011-2015). El kirchnerismo es un movimiento político de orientación peronista, fundado en 2003, bajo la coalición política Frente para la Victoria (FpV). El FpV se caracteriza por tener una política cultural activa, fue un bastión militante central en los gobiernos de Cristina Fernández, en particular desde 2011.

(3) Refiere al incendio ocurrido en la discoteca República Cromañón, durante el recital de la banda de rock barrial Callejeros, el 30 de diciembre de 2004. En la tragedia murieron 194 jóvenes.

(4) Aníbal lbarra fue Jefe de Gobierno de la ciudad de Buenos Aires desde agosto de 2000 hasta marzo de 2006; en ese año el juicio político por el incendio en "República Cromañón" lo destituyó de su cargo. Jorge Telerman ocupó el cargo de Jefe de Gobierno hasta diciembre de 2007. Lo sucedieron Mauricio Macri hasta diciembre de 2015 y Horacio Rodríguez Larreta quien actualmente ocupa el cargo (estos dos últimos provenientes del Partido Propuesta Republicana -PRO-).

(5) Actualmente, estos discursos se sustentan en acciones tales como las manifestaciones de protestas por parte de artistas (bajo el lema "El arte callejero no es delito") en contra de la reforma del Código Contravencional porteño propuesta por el Jefe de Gobierno Rodríguez Larreta, que propone criminalizar a artistas en la vía pública con sanciones como multas y prisión.

(6) Un desarrollo profundo sobre este tema puede encontrarse en el artículo "La organización de los jóvenes músicos independientes de rock de la Unión de Músicos de Avellaneda, Argentina, y su vínculo con el Municipio entre 2012 y 2017" (Saponara Spinetta, 2018), de la Revista EntreDiversidades.

(7) La Mesa, dependiente de la Dirección General de Cultura, Artes y Espectáculos de la Municipalidad de Avellaneda, comenzó a desarrollarse en agosto de 2017.

\section{Bibliografía}

Balbi, F. (2012). La integración dinámica de las perspectivas nativas en la investigación etnográfica. Intersecciones en Antropología, 13, pp. 485-499.

Clifford, J. (1995). Dilemas de la cultura. Barcelona: Gedisa. 
Fonseca, C. (2005). La clase social y su recusación etnográfica. Etnografías Contemporáneas, 1, pp. 117-138.

Garriga Zucal, J. y Salerno, D. (2008). Estadios, hinchas y rockeros: variaciones sobre el aguante. En Alabarces, P. y Rodríguez, M. G. (Comps.). Resistencias y mediaciones. Estudios sobre cultura popular (pp. 59-87). Buenos Aires: Paidós.

Geertz, C. (1994). Conocimiento local. Ensayos sobre la interpretación de las culturas. Barcelona: Gedisa.

Guber, R. (2001). La etnografía, método, campo y reflexividad. Bogotá: Grupo Editorial Norma.

Guber, R. (2014) Introducción. En Prácticas etnográficas. Ejercicios de reflexividad de antropólogos de campo (pp. 11-22). Buenos Aires: Instituto de Desarrollo Económico y Social-Miño y Dávila.

Lins Ribeiro, G. (1989). Decotidianizar. Extrañamiento y conciencia práctica, un ensayo sobre la perspectiva antropológica. Cuadernos de Antropología Social, 1, pp. 65-69.

Malinowski, B. (1995). Los argonautas del pacífico occidental. Barcelona: Península.

Perelman, M. (2013). Trabajar en los trenes. La venta ambulante en la Ciudad de Buenos Aires. Horizontes Antropológicos, 19(39), pp. 179-204.

Rockwell, E. (1987). Reflexiones sobre el proceso etnográfico (1982-1985). Centro de Investigación y de Estudios Avanzados del Instituto Politécnico Nacional, México.

Sarrabayrouse Oliveira, M. (2011). Poder Judicial y Dictadura. El caso de la Morgue. Buenos Aires: Centro de Estudios Legales y Sociales/Editores del Puerto.

Saponara Spinetta, V. (2018). La organización de los jóvenes músicos independientes de rock de la Unión de Músicos de Avellaneda, Argentina, y su vínculo con el Municipio entre 2012 y 2017. EntreDiversidades, revista de Ciencias Sociales y Humanidades, 1(10), pp. 99-125, Instituto de Estudios Indígenas, Universidad Autónoma de Chiapas.

Zenobi, D. (2010). O antropólogo como 'espião'. Das acusações públicas à construção das perspectivas nativas. Mana, 16, pp. 471-499. 